Studi Kasus

\title{
User Centered Design dan Evaluasi Iteratif pada Pengembangan Aplikasi DUPAK Perekayasa
}

\author{
Huda M. Elmatsani \\ Badan Pengkajian dan Penerapan Teknologi, Jl. MH. Thamrin 8, Jakarta 10340, Indonesia
}

\section{KATA KUNCI}

Prototyping, User Centered Design, Usabilitas, Aplikasi Web

\section{KORESPONDENSI}

Telepon: +62 85777171197

E-mail: huda.mohamad@bppt.go.id

\section{PENDAHULUAN}

Proses pengajuan dan penilaian Daftar Usulan Penetapan Angka Kredit (Dupak) merupakan kegiatan penting dalam karir pejabat fungsional perekayasa, karena pengajuan angka kredit merupakan cara menilaikan kinerja pekerjaannya yang menjadi dasar kenaikan jenjang dalam karirnya sebagai pejabat fungsional [1]. Sebuah aplikasi web dikembangkan guna menunjang kegiatan tersebut. Aplikasi web dipilih karena merupakan platform terbaik memanfaatkan teknologi saat ini untuk pengembangan dan penyediaan sistem informasi [2], proses pengembangan dan diseminasi lebih cepat dilaksanakan berkat majunya teknologi dan luasnya jaringan internet. Di sisi lain, web dapat digunakansebagai perangkat online dalam melakukan pengumpulan data yang efektif dan efisien[3], sehingga kegiatan mengumpulkan data-data pengajuan dan hasil penetapan angka kredit lebih tertib dan mudah dilaksanakan.

Namun, tidak setiap pengembangan aplikasi web berhasil dilaksanakan apabila pengembanagn sistem tidak memperhatikan faktor-faktor yang mendukung keberhasilannya, yang salah satu indikasinya adalah kepuasan stakeholder atau

\begin{abstract}
A B $\mathbf{S}$ T $\mathbf{R}$ A $\mathbf{C}$ T
Web technology and internet networks have made web applications the main tool in daily activities. But developing applications with limited time often leads to neglecting the role of the application to meet the needs and desires of the user. In this study we developed an positions by combining Incremental Prototyping and User Centered Design methods. The

Teknologi web dan jaringan internet telah menjadikan aplikasi web sebagai piranti utama dalam kegiatan sehari-hari. Namun pengembangan aplikasi dengan keterbatasan waktu usabilitas sehingga berdampak pada kegagalan aplikasi memenuhi kebutuhan dan keinginan penetapan angka kredit (DUPAK)untuk jabatan fungsional perekayasa dengan dikemangkan metode Incremental Prototyping dan User Centered Design. Aplikasi yang digunakan dalam pengajuan dan penilaian usulan angka kredit.
\end{abstract}

pengguna aplikasi [4]. Sebagaimana pada umumnya dalam pengembangan sistem, salah satu masalahyang sering terjadi adalah sistem yang tidak user friendlydan tidak selaras dengan apa yang dikerjakan penggunanya, yang menimbulkan kesulitan dalam pengoperasian dan ketidakpuasan yang disebabkan kegagalan dalam menjalankan tugas, padahal dengan rancangan antarmuka yang mudah dan tidak rumit akan memudahkan pengguna dalam mengoperasikannya [5].

Isu sentral pada masalah tersebut adalah usability pada rancangan antarmuka. Usability merupakan elemen kualitas pada aplikasi web, bersamaan dengan reliability dan security [6]. Menurut Nielsen [7], usability berhubungan dengan sistem yang mudah dipelajari, mudah dipahami, mudah digunakan, berfungsi sesuai tujuan pembuatan dan memberikan pengalaman memuaskan, yang semuanya direpresentasikan oleh rancangan antarmuka.

Dari sudut pandang pengguna, antarmuka adalah representasi dari sebuah aplikasi. Antarmuka yang tepat dapat meningkatkan pengalaman pengguna dalam berinteraksi dengan sistem [8]. Rancangan antarmuka yang baik dapat memberikan manfaat dan meningkatkan kinerja, seperti kepuasan dalam bekerja dan 
tingginya produktivitas. Rancangan antarmuka yang baik juga dapat menghemat biaya [9], sementara rancangan antar muka yang buruk dapat menimbulkan tekanan bagi pengguna, menurunkan kinerjadan mengurangi produktivitas. Dalam beberapa penelitian menunjukkan bahwa rancangan yang buruk, juga merupakan penyebab kegagalan pengembangan sistem[10].

User Centered Design (UCD) merupakan pendekatan dalam merancang sistem perangkat lunak untuk menghasilkan suatu sistem yang useful dan usable. UCD menekankan pada bagaimana memahami pengguna dan konteks penggunaannya dengan cara melibatkan pengguna dalam desain dan proses pengembangan[11]. Ben Shneiderman dalam bukunya Designing the User Interface: Strategies for Effective HumanComputer Interaction mengungkapkan delapan kaidah emas perancangan antarmuka, yang terdiri dari: konsistensi, penggunaan shortcut atau cara cepat melakukan tugas, informasi feedback ketika harus menunggu atau berhasil menyelesaikan suatu aksi, panduan untuk tugas yang memiliki tahapan, informasi yang memadai apabila terjadi error, adanya pilihan dalam melakukan aksi, adanya cara membatalkan aksi, antarmuka yang sederhana dan tidak ribet sehingga pengguna tak perlu menghapalkan langkah-langkah penggunaan [12]. Santi dan Fitriyah, dalam penelitiannya [13] menggunakan delapan kaidah emas untuk membuat sebuah rancangan yang menarik, namun sayangnya dalam melakukan evaluasi terhadap rancangan antarmuka mereka tidak melibatkan pengguna yang sebenarnya. Padahal, evaluasi desain yang melibatkan pengguna sangat penting untuk memastikan desain antarmuka menarik dan memenuhi kebutuhan pengguna [14].

Beberapa penelitian lain dijalankan untuk mengevaluasi rancangan antarmuka untuk aplikasi web [15],[16], baik dengan cara membuat angket sendiri atau menggunakan kuesioner tertentu. Secara umum, pada penelitian-penelitian tersebut, evaluasi desain dilangsungkan pada akhir fase pengembangan dan bukan pada tiap fase pengembangannya, sehingga hasil evaluasi tidak langsung menjadi umpan balik untuk memperbaiki sistem yang sedang dikembangkan.

Untuk mengatasi hal tersebut, perlu pengembangan sistem yang lebih cepat, yang dapat merespon dengan cepat masukanmasukan hasil evaluasi. Rapid Application Development (RAD) merupakan metode pengembangan sistem yang mengutamakan pengembangan prototype untuk mendapatkan feedback lebih cepat sehingga pembuatan aplikasi juga lebih cepat dituntaskan. Salah satu teknik yang diterapkan adalah incremental prototyping, yaitu proses pengembangan sistem secara iteratif [17]. Proses evaluasi desain terjadi pada setiap siklus prototype dan evaluasi desain dilakukan secara iteratif, diharapkan dengan proses iteratif maka hasil evaluasi desain dapat segera divisualisasikan pada prototype yang sedang dikem-bangkan.

Tujuan penelitian ini mengembangkan prototype aplikasi Dupak Perekayasa Online (DUPER) melalui pendekatan UCD dan melakukan evaluasi secara iteratif yang melibatkan para pengguna, agar aplikasi yang dikembangkan mudah dipelajari dan mudah digunakan, serta selaras dengan apa yang dikerjakan pengguna sehingga proses administrasi pengajuan usulan angka kredit secara online dapat dilaksanakan dengan baik dan tanpa kendala.

\section{METODOLOGI}

Framework pengembangan kerap digunakan dalam pembuatan aplikasi web, proses pengembangan menjadi lebih cepat dan desain antarmuka lebih mudah dan konsisten berkat tersedianya komponen-komponen antarmuka yang siap digunakan. Bootstrap merupakan framework pengembangan aplikasi paling populer, gratis dan open source[18], menyediakan template CSS dan fungsi-fungsi JavaScript yang diperlukan untuk menyajikan aplikasi web yang menarik dan interaktif.

Dengan penggunaan Bootstrap sebagai framework antarmuka, metode prototyping menjadi cukup efisien dan efektif dalam merancang antarmuka aplikasi. Keunggulan metode ini adalah produk akhir pengembangan sudah dapat dievaluasi sejak awal dan pada fase-fase pengembangan berikutnya, dan yang membuatnya efisien, prototype dapat menjadi aplikasi jadi yang nanti digunakan [19].

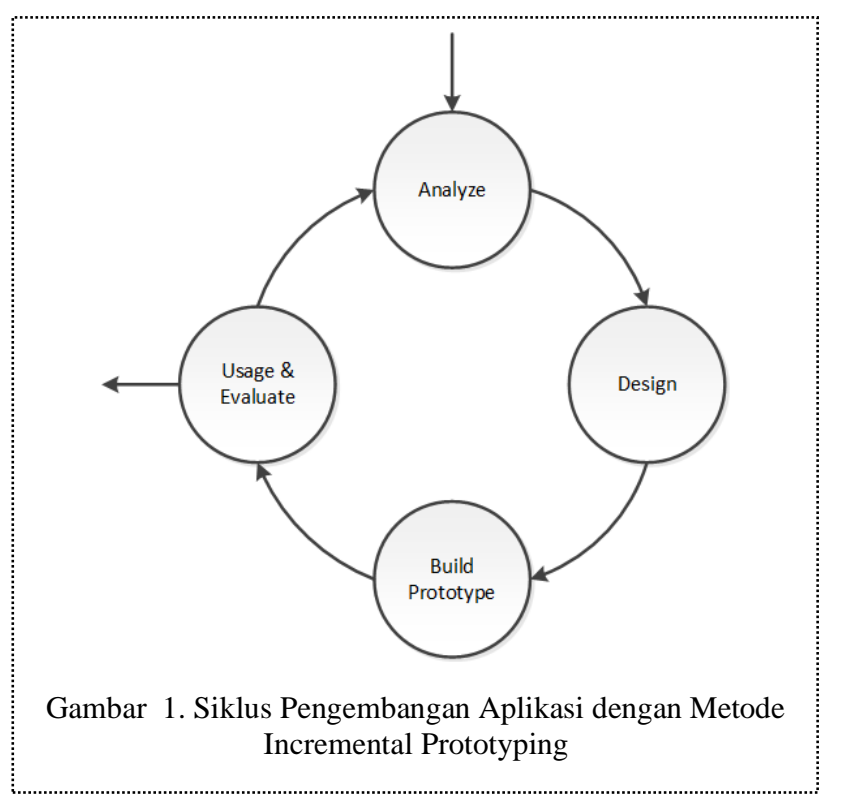

Gambar 1 menggambarkan siklus iteratif pengembangan secara prototyping, meliputi: (1) analyze, proses menganalisis kebutuhan pengguna dan sistem, dalam fase ini business proces dan skenario use case dirumuskan untuk mendapatkan gambaran ruang lingkup sistem dan detail dari setiap proses di dalamnya; (2) design, proses perancangan antarmuka untuk menerjemahkan kebutuhan pengguna menjadi rancangan antarmuka yang siap digunakan, pada tahapan ini metode 8 kaidah emas perancangan antarmuka diterapkan untuk mencapai usabilitas, (3) build prototype, proses coding yang mengubah rancangan menjadi prototype dan (4) usage \& evaluate, pengguna menggunakan prototype sekaligus melakukan evaluasi untuk menyempurnakan sistem yang dikembangkan [4]. Evaluasi merupakan fase yang sangat penting, yang memastikan sebuah aplikasi berguna dan mudah digunakan, menjadi kunci keberhasilan implementasi sebuah aplikasi.

Sebagaimana nampak pada gambar 1, setiap proses dalam siklus pengembangan prototype berlangsung secara iteratif dan terus menerus, mulai dari analyze, design, buid, sampai usage \& 
evaluate. Hal yang menjadi perhatian dalam evaluasi prototype adalah functionality dan usability dari desain antarmuka, pendekatan UCD digunakan, agar sistem memenuhi kebutuhan pengguna, mudah dipahami dan digunakan [20].

Proses evaluasi secara iteratif melibatkan peran serta dan peran aktif pengguna melalui tahapan sebagai berikut:

1. Iterasi pertama, pengembangan aplikasi ada pada tahapan perancangan antarmuka dan susunan menu aplikasi web untuk masing-masing pengguna, tujuan evaluasi ditekankan pada functionality, yaitu kesesuaian aplikasi dengan business process, melalui sebuah diskusi yang dihadiri perekayasa, penilai dan sekretariat sebagai para calon pengguna aplikasi. Dalam diskusi, peserta mengamati simulasi prototype yang sedang dikembangkan. Kemudian, peserta memberikan review dan masukan untuk perbaikan dan memberikan ide-ide fitur lain yang diperlukan;

2. Iterasi kedua, tahapan pengembangan aplikasi sudah sampai pada detail dari setiap proses, dalam artian bahwa prototype sudah dapat digunakan oleh pengguna untuk menyelesaikan tugasnya. Tujuan evaluasi adalah bagaimana para pengguna dapat menggunakan aplikasi sesuai dengan perannyamasingmasing, yaitu sebagai perekayasa, penilai dan sekretariat. Pada iterasi ini selain functionality, review terhadap usability dilakukan;

3. Iterasi ketiga merupakan pelaksanaan beta test, pengembangan aplikasi sudah pada tahap akhir di mana setiap fungsi aplikasi sudah diuji dan bekerja sesuai harapan. Aplikasi dapat digunakan secara nyata oleh perekayasa untuk mengajukan Dupak. Tujuan dari pengujian adalah bagaimana aplikasi dapat digunakan dalam konteks yang sebenarnya. Kegiatan dimulai dengan pembuatan panduan penggunaan aplikasi, sosialisasi aplikasi di lingkungan instansi, pelatihan bagi pegawai yang ditunjuk sebagai sekretariat, dan pelaksanaan penggunaan DUPER bagi para perekayasa yang berniat mengajukan angka kredit.

4. Iterasi selanjutnya adalah iterasi ke-n merupakan evaluasi berikutnya yang secara berkesinambungan berjalan sebagai bagian dari pengembangan dan pemeliharaan sistem.

Pengujian prototype dilaksanakan secara online. Prototype ditempatkan pada cloud server dengan alamat aplikasi web https://duper.bppt.go.id. Para pengguna mengakses aplikasi tersebut menggunakan notebook atau komputer desktop. Evaluasi terhadap prototype dan bagaimana pengguna melaksanakan tugas-tugasnya dilakukan melalui pengamatan dan diskusi.

Sebuah grup Whatsapp (WA) dibuat sebagai helpdesk dan tempat berdiskusi dalam kegiatan pengembangan dan implementasi DUPER. Penggunaan grup WA jugamenunjukkan bahwa interaksi antara pengguna dan pengembang aplikasi dapat berlangsung kapan saja, dan proses review tidak lagi dibatasi oleh ruang dan waktu.
Ada empat masukan yang diharapkan diperoleh dari proses pengujian dan review terhadap aplikasi, yaitu: bug report, kritik, saran perbaikan dan gagasan baru.

\section{HASIL DAN PEMBAHASAN}

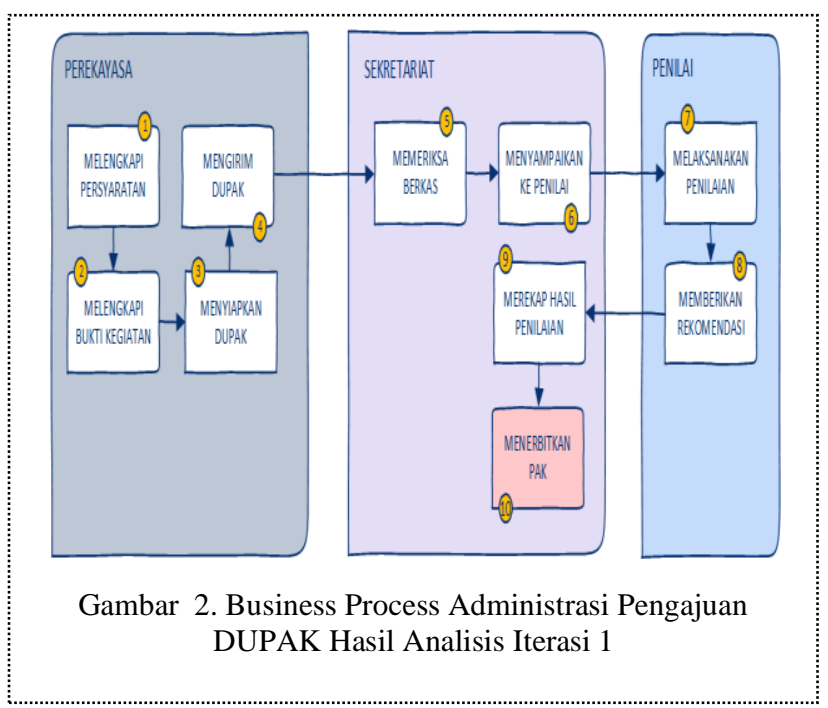

Fase analisis dari iterasi pertama menghasilkan diagram business process seperti ditunjukkan gambar 2 yang menjelaskan proses administrasi pengajuan Dupak yang disusun ke dalam tiga kelompok pelaksana kegiatan. Pelaksana kegiatan akan menjadi pengguna aplikasi dengan peran dan tugas sebagaimana diuraikan dalam Tabel 1.

Tabel 1. Daftar peran dan tugas pengguna dalam pengajuan DUPAK secara online dan menu terkait

\begin{tabular}{|c|c|c|c|c|}
\hline No & Peran & Deskripsi & Tugas & Menu \\
\hline 1 & $\begin{array}{l}\text { Perekay } \\
\text { asa }\end{array}$ & $\begin{array}{l}\text { Berperan } \\
\text { mengajuk } \\
\text { an } \\
\text { DUPAK }\end{array}$ & $\begin{array}{l}\text { - } \text { Melengka } \\
\text { pi } \\
\text { persyarata } \\
\text { n } \\
\text { - Melengka } \\
\text { pi bukti } \\
\text { kegiatan } \\
\text { - Menyiapk } \\
\text { an } \\
\text { DUPAK } \\
\text { - Mengirim } \\
\text { DUPAK } \\
\end{array}$ & $\begin{array}{ll}\text { - } & \text { Persy } \\
\text { aratan } \\
\text { - } \\
\text { Bukti } \\
\text { Kegia } \\
\text { tan } \\
\text { - Dupa } \\
\text { k }\end{array}$ \\
\hline 2 & $\begin{array}{l}\text { Sekretar } \\
\text { iat }\end{array}$ & $\begin{array}{l}\text { Berperan } \\
\text { memprose } \\
\text { s } \\
\text { DUPAK, } \\
\text { mulai dari } \\
\text { pemeriksa } \\
\text { an sampai } \\
\text { penerbitan } \\
\text { PAK }\end{array}$ & $\begin{array}{l}\text { - Memeriks } \\
\text { a DUPAK } \\
\text { - Mengemb } \\
\text { alikan } \\
\text { DUPAK } \\
\text { - Mendistri } \\
\text { busikan } \\
\text { ke Penilai } \\
\text { - Merekap } \\
\text { Hasil } \\
\text { Penilaian } \\
\text { - Menerbitk } \\
\text { an PAK }\end{array}$ & $\begin{array}{ll}\text { - } & \text { Dupa } \\
\mathrm{k} \\
\text { - } & \text { Penu } \\
\text { gasan } \\
\text { - Hasil } \\
\text { Penil } \\
\text { - } \text { aian } \\
\text { PAK }\end{array}$ \\
\hline
\end{tabular}




\begin{tabular}{llll}
\hline 3 Penilai & Berperan & - Melaksan & $\bullet$ Dupa \\
& melakuka & akan & $\mathrm{k}$ \\
& $\mathrm{n}$ & Penilaian & $\bullet$ Penil \\
& penilaian & - Memberik & aian \\
& terhadap & an & \\
& DUPAK & Rekomen & \\
& & dasi & \\
& & & \\
& & &
\end{tabular}

Berdasarkan informasi pada business process maka menu untuk setiap pengguna dirumuskan melalui tugas untuk masing-masing peran. Ada tiga peran yang teridentifikasi dalam business process, yaitu: perekayasa, sekretariat dan penilai. Peran pertama adalah perekayasa, pengguna yang paling berkepentingan dengan dibuatnya aplikasi, yang mempunyai tugas menyiapkan, mengirimkan usulan angka kredit dan memperoleh penetapan angka kredit (PAK). Adapun peranperan lainnya, mempunyai tugas memproses Dupak yang diajukan perekayasa.

Pada iterasi pertama, kami hanya mengembangkan antarmuka untuk perekayasa. Ruang lingkup yang terbatas ini dimaksudkan agar tidak terlalu banyak permasalahan yang harus ditangani, sehingga kerangka dasar aplikasi dapat terbentuk dengan baik dan bekerja dengan stabil.

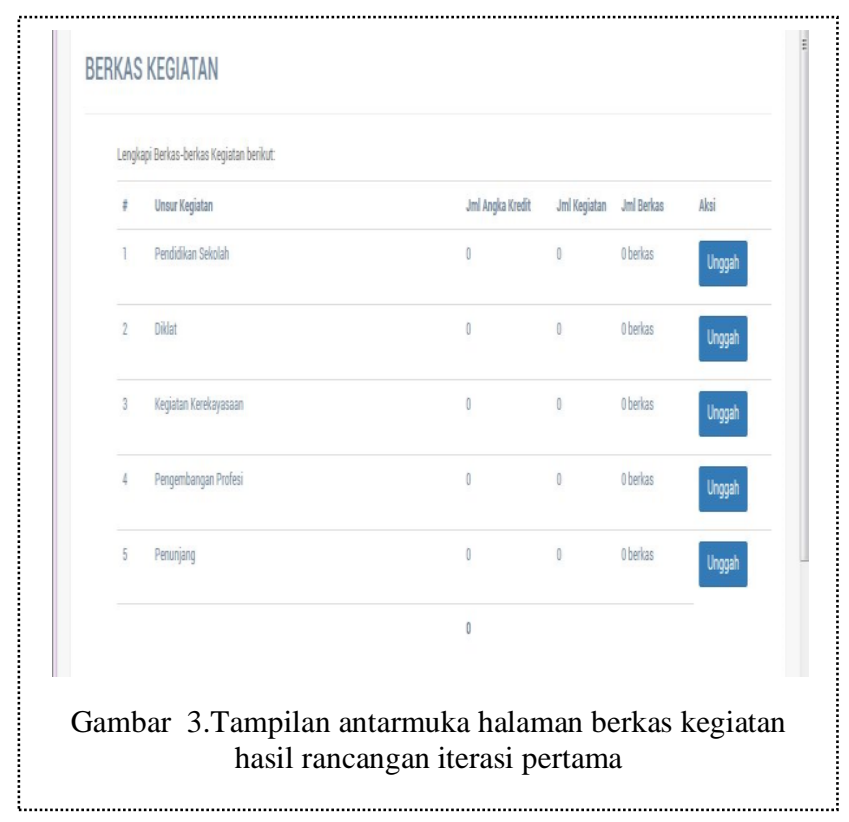

Gambar 3 memperlihatkan salah satu antarmuka aplikasi pada halaman unggah bukti kegiatan yang dibuat dengan penyajian sederhana, dengan harapan perekayasa dapat dengan mudah memahami dan menggunakannya.

Evaluasi prototype pada iterasi pertama dilaksanakan dalam sebuah pertemuan, dihadiri tujuh orang peserta yang terdiri dari 3 perekayasa, 2 anggota tim penilai, 2 anggota sekretariat dan 3 orang tim IT. Pada evaluasi ini, perekayasa melakukan pengujian dengan melakukan pengisian data pada prototype aplikasi. Ada empat tahapan proses yang dilalui, yaitu: melengkapi persyaratan, melengkapi dan mengunggah bukti kegiatan, menyiapkan DUPAK dan mengirimkannya. Beberapa catatan dan masukan yang menjadi perhatian dalam pengembangam aplikasi disajikan dalam Tabel 2 .
Tabel 2. Catatan dan masukan penting pada review iterasi pertama

\begin{tabular}{|c|c|c|c|}
\hline No & Uraian & Kategori & Tanggapan/Solusi \\
\hline 1 & $\begin{array}{l}\text { Login aplikasi } \\
\text { sebaiknya } \\
\text { menggunakan } \\
\text { login email } \\
\text { resmi } \\
\text { lembaga }\end{array}$ & Saran & $\begin{array}{l}\text { Gunakan API LDAP } \\
\text { untuk login }\end{array}$ \\
\hline 2 & $\begin{array}{l}\text { Siapakah } \\
\text { yang } \\
\text { mengunggah } \\
\text { program } \\
\text { manual? }\end{array}$ & $\begin{array}{l}\text { Penasara } \\
\mathrm{n}\end{array}$ & $\begin{array}{l}\text { Perlu dibuat peran } \\
\text { sekretariat unit kerja } \\
\text { bertugas mengunggah } \\
\text { program manual }\end{array}$ \\
\hline 3 & $\begin{array}{l}\text { Apakah } \\
\text { persyaratan } \\
\text { administrasi } \\
\text { harus } \\
\text { diunggah } \\
\text { kembali } \\
\text { setiap kali } \\
\text { mengajukan? }\end{array}$ & $\begin{array}{l}\text { Penasara } \\
\mathrm{n}\end{array}$ & $\begin{array}{l}\text { Perlu dibuat komponen } \\
\text { yang berisi berkas- } \\
\text { berkas kepegawaian }\end{array}$ \\
\hline 4 & $\begin{array}{l}\text { Data pegawai } \\
\text { sebaiknya } \\
\text { diambil dari } \\
\text { Sistem Data } \\
\text { Terpadu } \\
\text { (SIDADU) }\end{array}$ & Saran & $\begin{array}{l}\text { Gunakan API SIDADU } \\
\text { untuk memperoleh data } \\
\text { pegawai }\end{array}$ \\
\hline 5 & $\begin{array}{l}\text { Pada } \\
\text { informasi } \\
\text { pengguna, } \\
\text { sebaiknya } \\
\text { ditampilkan } \\
\text { data jabatan } \\
\text { dan pangkat }\end{array}$ & Saran & Siap dilaksanakan \\
\hline 6 & $\begin{array}{l}\text { Butir kegiatan } \\
\text { sebaiknya } \\
\text { ditampilkan } \\
\text { secara } \\
\text { otomatis } \\
\text { sesuai dengan } \\
\text { perannya }\end{array}$ & Saran & Siap dilaksanakan \\
\hline 7 & $\begin{array}{l}\text { Bagaimana } \\
\text { caranya tim } \\
\text { penilai } \\
\text { melakukan } \\
\text { penilaian } \\
\text { terhadap bukti } \\
\text { kegiatan yang } \\
\text { biasanya bisa } \\
\text { dengan cara } \\
\text { mencoret- } \\
\text { coret dan } \\
\text { memberikan } \\
\text { catatan? }\end{array}$ & $\begin{array}{l}\text { Penasara } \\
\mathrm{n}\end{array}$ & $\begin{array}{l}\text { Bisa dicetak dulu baru } \\
\text { dinilai, atau ubah cara } \\
\text { penilaiannya }\end{array}$ \\
\hline
\end{tabular}

Catatan-catatan tersebut umumnya berkaitan dengan usability aplikasi. Sebagai contoh pada catatan tentang login, saran yang diberikan adalah menggunakan login email resmi lembaga. Untuk menerima saran ini maka perlu modifikasi pada functionality aplikasi, yaitu penggunaan API LDAP untuk mengakses server email lembaga untuk melakukan proses otentikasi. Login menjadi lebih mudah bagi pengguna, karena pengguna tidak perlu lagi registrasi atau membuat akun baru untuk bisa mengakses aplikasi. Demikian juga halnya dengan penyajian data pegawai. Integrasi dengan SIDADU (Sistem 
Informasi/Data Terpadu) membuat data yang digunakan dipastikan valid dan pengguna tidak perlu lagi menginput data dirinya. Catatn lain dalam evaluasi pertama adalah ada berbagai masukan dan pertanyaan terkait pengembangan dan implementasi aplikasi, kesiapan infrastruktur, SDM dan peraturan resmi yang mendukungnya.

Pada iterasi kedua, di mana tujuannya adalah seluruh menu dan proses diharapkan sudah dapat berfungsi, ada beberapa kegiatan yang dilakukan, yaitu: (1) memperbaiki business process, (2) mengerjakan rancangan antarmuka untuk semua komponen pengguna, (3) membuat prototype secara lebih rinci sehingga setiap pengguna dapat melaksanakan tugas-tugasnya sampai selesai, dan (4) melakukan evaluasi dengan cara menguji cobakan aplikasi dalam lingkungan terbatas.

Terdapat koreksi terhadap business process, yaitu penambahan peran sekretariat unit kerja. Peran ini mempunyai tanggung jawab menjalankan tugas mengunggah berkas yang menjadi syarat pengajuan Dupak, berkas yang digunakan bersama oleh para perekayasa, seperti berkas program manual dan struktur OFK.

OFK singkatan dari Organisasi Fungsional Kerekayasaan, merupakan organisasi yang dibentuk untuk menjalankan kegiatan kerekayasaaan. Bukti kegiatan yang diunggah seorang perekayasa menjadi tidak valid bila perekayasa tidak bisa menunjukkan keanggotannya dalam OFK. Dengan tersedianya OFK pada aplikasi, maka perekayasa dapat memilih di OFK mana ia terlibat dan dapat melaporkan kegiatannya berdasarkan perannya di OFK tersebut.

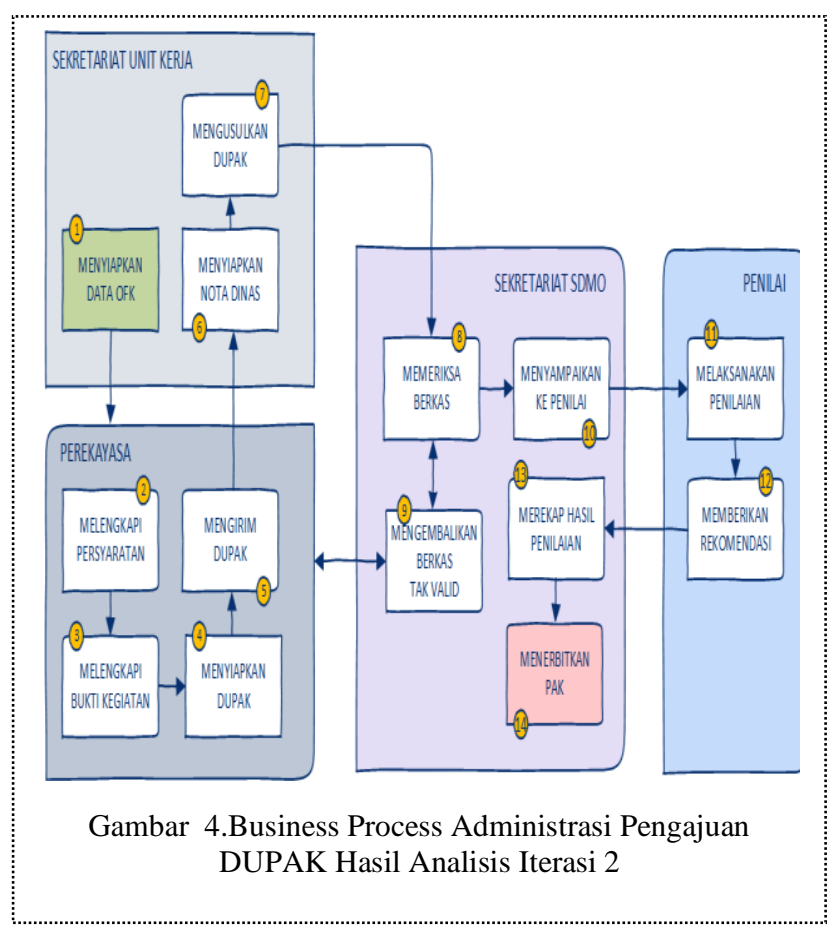

Gambar 4 menunjukkan diagram business process yang telah mengalami penyesuaian berdasarkan diskusi pada evaluasi iterasi pertama. Ada penambahan peran berupa sekretariat unit kerja. Sekretariat unit kerja adalah sekretariat di mana perekayasa bekerja. Sekretariat unit kerja bertanggung jawab dalam menyiapkan data-data OFK dan menyiapkan nota dinas untuk pengusulan DUPAK dari para perekayasa di unit kerjanya.

Tabel 3. Daftar menu dan jumlah antarmuka untuk masingmasing komponen

\begin{tabular}{cllc}
\hline No & Komponen & \multicolumn{1}{c}{ Menu } & $\begin{array}{c}\text { Jumlah } \\
\text { Antarmuka }\end{array}$ \\
\hline 1 & $\begin{array}{l}\text { Sekretariat } \\
\text { Unit Kerja }\end{array}$ & $\begin{array}{l}\text { OFK, Dupak, } \\
\text { Usulan }\end{array}$ & 3 \\
\hline 2 & Perekayasa & Dupak, OFK & 10 \\
\hline 3 & Sekretariat & $\begin{array}{l}\text { Usulan, Dupak, } \\
\text { Instansi }\end{array}$ & $\begin{array}{l}\text { Penugasan, Hasil } \\
\text { Penilaian, }\end{array}$ \\
& & $\begin{array}{l}\text { Penilai, } \\
\text { PAK }\end{array}$ & \\
& & $\begin{array}{l}\text { Dupak, Penilaian, } \\
\text { Hasil Penilaian }\end{array}$ & 3 \\
\hline 4 & Penilai &
\end{tabular}

Desain antarmuka pada iterasi 2 meliputi komponen-komponen sekretariat unit kerja, perekayasa, sekretariat instansi, dan penilai. Tabel 3 menjelaskan antarmuka-antarmuka yang harus dibuat untuk komponen-komponen tersebut.

Evaluasi prototype pada iterasi kedua berlangsung dalam sebuah workshop yang dihadiri 15 orang, terdiri dari 4 perekayasa, 3 anggota tim penilai, 2 anggota sekretariat, 3 orang tim IT dan 3 orang dari manajemen.

Evaluasi dilaksanakan dengan cara simulasi penggunaan aplikasi. Langkah demi langkah diperagakan sampai proses dapat dituntaskan sesuai dengan business process dalam pengajuan DUPAK. Masing-masing peran dimainkan peserta rapat dengan tugas-tugas yang harus dilaksanakan mengikuti alur proses pengajuan dan penilaian. Secara umum, harapannya adalah sebuah DUPAK berhasil dinilaikan.

Tabel 4. Daftar peran penguji, tugasnya, keberhasilan dan catatan kendala yang dihadapi

\begin{tabular}{|c|c|c|c|c|}
\hline No & $\begin{array}{c}\text { Peran } \\
\text { Penguji }\end{array}$ & Tugas & $\begin{array}{l}\text { Tingkat } \\
\text { Berhasil }\end{array}$ & Kendala \\
\hline 1 & $\begin{array}{l}\text { Sekretari } \\
\text { at Unit } \\
\text { Kerja }\end{array}$ & $\begin{array}{l}\text { Menyusun } \\
\text { OFK dan } \\
\text { mengusulk } \\
\text { an DUPAK } \\
\text { yang } \\
\text { diajukan } \\
\text { perekayasa }\end{array}$ & $100 \%$ & $\begin{array}{ll}\text { - } & \text { Peran } \\
\text { dalam OFK } \\
\text { tidak bisa } \\
\text { diedit/dihap } \\
\text { us } \\
\text { - } \\
\text { Tidak bisa } \\
\text { memasukka } \\
\text { n nama non } \\
\text { pegawai }\end{array}$ \\
\hline 2 & $\begin{array}{l}\text { Perekaya } \\
\text { sa }\end{array}$ & $\begin{array}{l}\text { Menyusun } \\
\text { DUPAK } \\
\text { dan } \\
\text { mengirimk } \\
\text { annya }\end{array}$ & $100 \%$ & $\begin{array}{l}\text { - Mengungga } \\
\text { h buku (file } \\
\text { ukuran } \\
\text { besar) }\end{array}$ \\
\hline 3 & $\begin{array}{l}\text { Sekretari } \\
\text { at } \\
\text { Instansi }\end{array}$ & $\begin{array}{l}\text { Memeriksa } \\
\text { DUPAK } \\
\text { dan } \\
\text { menugaska } \\
\text { n penilaian } \\
\text { ke seorang } \\
\text { penilai }\end{array}$ & $50 \%$ & $\begin{array}{l}\text { - Belum ada } \\
\text { antarmuka } \\
\text { penugasan }\end{array}$ \\
\hline 4 & Penilai & $\begin{array}{l}\text { Memeriksa } \\
\text { DUPAK } \\
\text { dan } \\
\text { menilainya, }\end{array}$ & $30 \%$ & 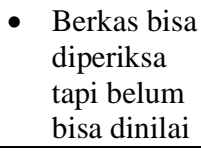 \\
\hline
\end{tabular}

DOI: https://doi.org/10.30743/infotekjar.v3i2.1014 
dan

mengirimk

an hasil

penilaian

Tabel 4 menunjukkan hasil simulasi pengujian prototype. Hasilnya tidak sempurna, namun cukup memuaskan mengingat ada hasil-hasil penting yang sudah tercapai, seperti penyusunan OFK dan DUPAK. Dalam pengamatan juga tercatat bahwa umumnya pengguna tidak mengalami kesulitan dalam menjelajahi aplikasi, membuka menu dan melakukan aktivitas sesuai dengan tugas-tugas dalam perannya. Hal ini menunjukkan bahwa rancangan antarmuka cukup berhasil dalam menyajikan prototype yang user friendly.

Ada masukan dalam pengujian berupa pertanyaan dan kendala. Pertanyaan dan kendala seringkali tidak membutuhkan jawaban, karena merupakan jawaban yang memiliki gagasan penting bagaimana sistem harus diperbaiki dan disempurnakan.Beberapa masukan diterima seperti: OFK yang tidak bisa diedit, input personel non pegawai yang tidak bisa diinput, antarmuka penugasan dan antarmuka penilaian yang belum tersedia. Secara umum permasalahan disebabkan dua hal, yaitu bugs dan modulnya belum digarap. Kedua masalah ini menjadi catatan untuk perbaikan pada iterasi berikutnya.

Pada iterasi ketiga atau beta test, tujuan pengujian adalah agar prototype dapat digunakan dalam pengajuan DUPAK yang sebenarnya. Diharapkan sesudah berhasil melewati beta test, aplikasi dapat diformalkan untuk digunakan secara resmi dalam pengajuan usulan angka kredit jabatan fungsional perekayasa secara nasional.

Langkah-langkah sebelum melaksanakan beta test, meliputi:

1. Pemeriksaan dan perbaikan terhadap seluruh antarmuka dan proses, untuk memastikan pengguna dapat menyelesaikan tugasnya tanpa hambatan dan masalah;

2. Penyusunan buku panduan untuk perekayasa, sekretariat dan penilai;

3. Sosialisasi kepada para perekayasa melalui forum, web dan media sosial;

4. Pelatihan untuk sekretariat unit kerja, khususnya dalam melakukan penyusunan OFK;

5. Pelaksanaan pengujian yang diharapkan diikuti oleh perekayasa yang bermaksud mengajukan DUPAK untuk penambahan angka kredit.

Hasil pemeriksaan status kesiapan antarmuka untuk masingmasing komponen disajikan dalam Tabel 5.

Tabel 5. Daftar status kesiapan antarmuka untuk masing-masing komponen

\begin{tabular}{cll}
\hline Komponen & \multicolumn{1}{c}{ Antarmuka } & Status \\
\hline Sekretariat & Daftar OFK & OK \\
\cline { 2 - 3 } Unit Kerja & Edit OFK & OK \\
\cline { 2 - 3 } & Daftar Usulan & OK \\
\cline { 2 - 3 } & Daftar DUPAK & OK \\
\hline Perekayasa & Daftar DUPAK & OK \\
\cline { 2 - 3 } & Daftar Syarat Adm & OK \\
\cline { 2 - 3 } & Unggah Syarat Adm & OK \\
\hline
\end{tabular}

DOI: https://doi.org/10.30743/infotekjar.v3i2.1014

\begin{tabular}{lll}
\hline & \multicolumn{1}{l}{ Bukti Kegiatan } & OK \\
\cline { 2 - 3 } & Unggah Pendidikan & OK \\
\cline { 2 - 3 } & Unggah Pelatihan & OK \\
\cline { 2 - 3 } & Unggah Profesi & OK \\
\cline { 2 - 3 } & Unggah Kerekayasaan & OK \\
\cline { 2 - 3 } & Unggah Penunjang & OK \\
\cline { 2 - 3 } & Daftar Pernyataan & OK \\
\cline { 2 - 3 } & Kirim DUPAK & OK \\
\cline { 2 - 3 } Daftar OFK & OK \\
\hline \multirow{2}{*}{ Instansi } & Usulan & OK \\
\cline { 2 - 3 } & Daftar DUPAK & OK \\
\cline { 2 - 3 } & Periksa DUPAK & OK \\
\cline { 2 - 3 } & Penugasan & OK \\
\cline { 2 - 3 } & Hasil Penilaian & OK \\
\cline { 2 - 3 } & Penilai & OK \\
\cline { 2 - 3 } & Daftar PAK & OK \\
\hline Penilai & Daftar DUPAK & OK \\
\cline { 2 - 3 } & Penilaian DUPAK & \\
\cline { 2 - 3 } & Hasil Penilaian & \\
& &
\end{tabular}

Dari 26 antarmuka, hanya ada 2 antarmuka yang belum siap, atau status kesiapannya sudah lebih dari $90 \%$. Selain itu, untuk komponen perekayasa, status kesiapannya sudah $100 \%$, artinya aplikasi sudah siap digunakan oleh perekayasa yang akan mengajukan Dupak. Penyusunan buku panduan untuk perekayasa pun mulai dilakukan karena untuk semua antarmuka yang dibutuhkan dalam panduan sudah bisa di-screenshot.

Beta test dilaksanakan selama tiga minggu. Rentang waktu tak cukup panjang, namun cukup luang untuk perekayasa yang sudah menyiapkan berkas-berkasnya dan memahami cara mengguna-kan aplikasi. Pemantauan terhadap pelaksanaan pengujian dilakukan melalui pengamatan terhadap data-data yang masuk ke dalam sistem dan pemantauan terhadap pertanyaan-pertanyaan yang disampaikan lewat grup WA.

Gambar 5 merupakan rekapitulasi data hasil pelaksanaan beta test yang menunjukkan jumlah pengajuan DUPAK. Total DUPAK yang diajukan berjumlah 195, dengan rincian 81 DUPAK diajukan untuk periode Oktober 2018, 72 DUPAKdiajukan untuk April 2019, 7 DUPAKdiajukan untuk Oktober 2019, dan 35 DUPAKtidak menentukan periode pengajuannya. Sekalipun baru diperkenalkan, jumlah Dupak yang diajukan cukup banyak, fenomena ini mengindikasikan besarnya minat dan antusiasme para perekayasa dalam mengajukan DUPAKsecara online.

Grafik juga menunjukkan bahwa ada 5 DUPAKyang akhirnya dikirimkan. Ini menunjukkan bahwa aplikasi sudah bisa digunakan dalam menyusun dan mengirimkan DUPAK, sekalipun tidak banyak namun memberikan data penting pada hasil pengujian. Di sisi lain, DUPAKyang masuk, menjadi bahan pengujian bagi para penilai dalam melakukan pemeriksaan dan penilaian bukti kegiatan menggunakan aplikasi DUPER.

Hasil review pada iterasi-3 lebih banyak pada aspek implementasi aplikasi. Misalnya, untuk meningkatkan jumlah DUPAK yang dikirimkan, perlu persiapan yang lebih matang, sosialisasi yang lebih luas, bimbingan teknis di unit-unit kerja 
dan penerbitan peraturan yang memformalkan penggunaan DUPER sebagai cara dalam mengirimkan DUPAK.

\section{KESIMPULAN}

Metode incremental prototyping dan pendekatan UCD yang melibatkan pengguna terbukti dapat menghasilkan prototype aplikasi DUPER yang useful dan usable. Proses evaluasi secara iteratif memperlihatkan bagaimana pengembangan dan perbaikan prototype menjadi lebih efektif dan hasil pengujian menunjukkan bahwa aplikasi web yang dirancang dan dibuat benar-benar sesuai harapan dan dapat digunakan dalam pengajuan DUPAK secara online. Pada penelitian ini, evaluasi lebih ditekankan pada bagaimana aplikasi mudah dipahami dan mudah digunakan. Untuk lebih meningkatkan usabilitas maka pada penelitian berikutnya perlu evaluasi yang menilai pengalaman pengguna dan mengukur seberapa puas pengguna menggunakan aplikasi.

\section{DAFTAR PUSTAKA}

[1] Perka BKN No 13, "Petunjuk Teknis Pelaksanaan Pembinaan jabatan Fungsional Perekayasa dan Angka Kreditnya.” Badan kepegawaian Negara, Jakarta, 2016.

[2] I. T. Handoyo, "A Review of Web-based Information System for Decision Support Context," pp. 275-280, 2017.

[3] C. J. Cooper, S. P. Cooper, D. J. del Junco, E. M. Shipp, R. Whitworth, and S. R. Cooper, "Webbased data collection: detailed methods of a questionnaire and data gathering tool.," Epidemiol. Perspect. Innov., vol. 3, no. April, p. 1, 2006.

[4] M. Guntur and B. Purwandari, "Critical Success Factors for Information Systems Development : A Case Study in e-Government," pp. 1-5, 2018.

[5] A. Nurlifa, S. Kusumadewi, and Kariyam, "Analisis Pengaruh User Interface terhadap Kemudahan Penggunaan Sistem Pendukung Keputusan Seorang Dokter," Pros. SNATIF, vol. 1, pp. 333-340, 2014.

[6] J. Offutt, "Quality attributes of Web software applications," IEEE Softw., vol. 19, no. 2, pp. 2532, 2002.

[7] C. Altin Gumussoy, "Usability guideline for banking software design," Comput. Human Behav., vol. 62, pp. 277-285, 2016.

[8] A. A. Akhsan and Faizah, "Analisis dan Perancangan Interaksi Chatbot Reminder dengan User-Centered Design," J. Sist. Inf., vol. 13, no. 2, pp. 78-89, 2017.

[9] F. E. Ritter, G. D. Baxter, and E. F. Churchill, Foundations for Designing User-Centered Systems. 2014.

[10] S. K. Bagdi, "Why do Some of the HIRS Implementations Fail," in Practical Human Resource Information Systems, New Delhi: PHI Learning Pvt. Ltd, 2012, pp. 1-32.

[11] E. Eshet and H. Bouwman, "Context of Use: The Final Frontier in the Practice of User-Centered
Design?," Interact. Comput., vol. 29, no. 3, pp. 368-390, 2017.

[12] D. L. Hansen, B. Shneiderman, and M. A. Smith, "Social Media New Technologies of Collaboration," in Analyzing Social Media Networks with NodeXL, 2011, pp. 11-29.

[13] R. Candra, N. Santi, and A. Fitriyah, "Perancangan Interaksi Pengguna ( User Interaction Design ) Menggunakan Metode Prototyping," vol. 9, no. 2, pp. 108-113, 2016.

[14] R. S. Pressman, "Interface Design," in Software Engineering A Practitioner's Approach 7th, McGraw-Hill Education, 2010.

[15] E. Susilo, F. D. Wijaya, and R. Hartanto, "Perancangan dan Evaluasi User Interface Aplikasi Smart Grid Berbasis Mobile Application," Jnteti, vol. 7, no. 2, pp. 150-157, 2018.

[16] Z. Huang and M. Benyoucef, "Usability and credibility of e-government websites," Gov. Inf. Q., vol. 31, no. 4, pp. 584-595, 2014.

[17] C. Carne, H. Mackay, and D. Tudhope, "Rapid application development ( RAD ): an empirical review," vol. 1, pp. 211-223, 1999.

[18] V. Balasubramanee and M. Pierce, "Twitter Bootstrap and AngularJS Frontend Frameworks to expedite Science Gateway development," p. 4799, 2013.

[19] M. Bochicchio and R. Paiano, "Prototyping web applications," Proc. ACM Symp. Appl. Comput., vol. 2, pp. 978-983, 2000.

[20] G. F. Grade, "Hci and Its Effective Use in Design and Development of Good User Interface," pp. 176-180, 2014.

\section{BIODATA PENULIS}

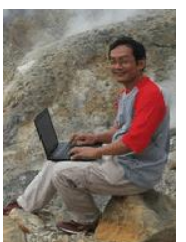

Huda M. Elmatsani

Berkarirdi Badan Pengkajian dan Penerapan Teknologi sebagai Perekayasa dengan kompetensi pada bidang software engineering, web design, graphic design dan photography. 